\title{
Pomalidomide: a novel drug to treat relapsed and refractory multiple myeloma
}

This article was published in the following Dove Press journal:

OncoTargets and Therapy

9 May 2013

Number of times this article has been viewed

\section{Evangelos Terpos \\ Nikolaos Kanellias \\ Dimitrios Christoulas \\ Efstathios Kastritis \\ Meletios A Dimopoulos}

Department of Clinical Therapeutics, University of Athens School of Medicine, Alexandra University Hospital, Athens, Greece
Correspondence: Meletios A Dimopoulos Department of Clinical Therapeutics, University of Athens School of Medicine, Alexandra University Hospital, 80 Vas Sofias Avenue, II 28 ,

Athens, Greece

Tel +302132162540

$\mathrm{Fax}+302132162511$

Email mdimop@med.uoa.gr
Abstract: Multiple myeloma remains an incurable disease despite the introduction of the immunomodulatory drugs (IMiDs) thalidomide and lenalidomide and the proteasome inhibitor bortezomib that have improved the outcome of patients with both newly diagnosed and relapsed/ refractory disease. However, patients who relapse after treatment with these agents or are refractory to them represent an unmet need and highlight the necessity for the development of novel anti-myeloma agents. Pomalidomide is an IMiD, structurally related to thalidomide, with enhanced antiangiogenic, antineoplastic, and anti-inflammatory properties and exhibiting potent anti-myeloma activity in vitro and in vivo. Pomalidomide has shown remarkable activity in patients who were refractory to both bortezomib and lenalidomide in Phase II and III studies. This paper reviews the chemistry and mechanisms of action of pomalidomide as well as all the available data from clinical trials on pomalidomide use in patients with refractory/relapsed multiple myeloma.

Keywords: immunomodulatory drugs, cereblon, angiogenesis, lenalidomide, refractory

\section{Introduction}

Multiple myeloma (MM) is a plasma cell malignancy characterized by the monoclonal expansion and accumulation of plasma cells in the bone marrow. The incidence of multiple myeloma in Europe is 6/100,000/year while, in USA, 20,000 new cases are diagnosed every year and 11,000 people die because of the disease every year. ${ }^{1}$ For several decades, the treatment of MM included combinations of chemotherapeutic agents with steroids for elderly patients and high-dose melphalan followed by autologous stem-cell transplantation after an induction with the combination vincristine/doxorubicin/dexamethasone for patients $<65-70$ years. ${ }^{2}$ Advances in the understanding of the biology of myeloma cells and their interaction with the microenvironment, as well as the comprehension of the underlying molecular pathways, led to the development of novel compounds. The introduction of the immunomodulatory drugs (IMiDs) thalidomide and lenalidomide and the proteasome inhibitor bortezomib, used either as single agents or combined with classic anti-myeloma therapies, has improved the outcome for patients with newly diagnosed and relapsed/refractory MM. ${ }^{3,4}$ Nevertheless, MM remains an incurable disease. Even in patients who achieve stringent complete response (sCR), the disease will inevitably relapse, highlighting the necessity for the development of novel anti-myeloma agents. Pomalidomide is a lead compound of the third-generation IMiDs and has been tested with very encouraging results in MM patients, especially in those who have been refractory to both lenalidomide- and bortezomib-based therapies. This paper reviews the chemistry and mechanisms of action of pomalidomide as well as all the available data from reported clinical trials on pomalidomide use in patients with refractory and relapsed MM. 


\section{Pharmacologic and pharmacokinetic properties of pomalidomide}

Pomalidomide and lenalidomide are structurally related to thalidomide. Thalidomide was the first IMiD discovered; thalidomide had correlated with severe congenital malformations in the past and, was found to be effective in patients with refractory MM in the late 1990s..$^{5}$ The effects of thalidomide were attributed to its antiangiogenic and immunomodulatory activity. ${ }^{6}$ Novel IMiDs with more potent anti-inflammatory activities and a more favorable toxicity profile were created by chemical modifications to the structural backbone of thalidomide. Pomalidomide has an additional amino group in the fourth carbon of the phthaloyl ring. It also differs from lenalidomide in that it has an additional carbonyl group in the phthaloyl ring (Figure 1). The chemical name of pomalidomide is 4-amino-2-(2,6-dioxopiperidin-3-yl)isoindoline1,3-dione, and its empirical formula is $\mathrm{C}_{13} \mathrm{H}_{11} \mathrm{~N}_{3} \mathrm{O}_{4}$, with a molecular weight of 273.24 Da. Following oral administration, pomalidomide is well absorbed, with parent compound being the predominant circulating component. Maximum plasma concentration $\left(\mathrm{C}_{\max }\right)$ occurs 3 hours post-dose. Pomalidomide is extensively metabolized prior to excretion, and metabolites are eliminated primarily in urine. ${ }^{7}$ Clearance pathways include cytochrome P450-mediated hydroxylation with subsequent glucuronidation ( $43 \%$ of the dose), glutarimide ring hydrolysis (25\%), and excretion of unchanged drug (10\%). 5-Hydroxy pomalidomide, the notable oxidative metabolite, is formed primarily via CYP1A2 and CYP3A4. The hydroxy metabolites and hydrolysis products are at least 26-fold less pharmacologically active than pomalidomide in vitro. ${ }^{7}$

\section{Mechanisms of action of pomalidomide}

IMiDs have shown several activities regarding the treatment of MM, such as direct induction of myeloma cell apoptosis, immunomodulation, and inhibition of angiogenesis. Angiogenesis is increased in MM and related to disease progression. The major angiogenic cytokines, vascular endothelial growth factor (VEGF) and basic fibroblast growth factor (bFGF), are expressed by myeloma cells. ${ }^{8}$ Antiangiogenic action of IMiDs has been documented in mouse models of human tumors. ${ }^{9}$ IMiDs indirectly inhibit endothelial cell proliferation by inhibiting the secretion of VEGF and bFGF from both myeloma and stromal cells. ${ }^{10,11}$ In addition, IMiDs inhibit cytokine-stimulated endothelial cell migration and cell adhesion in some experimental models. ${ }^{12}$ IMiDs induce apoptosis or G1 growth arrest, in MM cell lines and in patients' MM cells that are resistant to melphalan, doxorubicin, and dexamethasone. Moreover, IMiDs enhance the anti-MM activity of dexamethasone associated with activation of related adhesion focal tyrosine kinase..$^{13}$ IMiDs also promote apoptosis of MM cells through enhanced activity of caspase-8, increased sensitivity to Fas induction, inhibition of the expression of the cellular inhibitor of apoptosis protein-2, and potentiation of other apoptosis inducers, such as tumor necrosis factor (TNF)-related apoptosisinducing ligand. ${ }^{14} \mathrm{IMiDs}$ reduce the secretion of interleukin (IL)-6 and VEGF, important growth factors for MM cell survival and proliferation, by inhibiting MM cell adhesion to bone marrow stromal cells through downregulation of the expression of cell adhesion molecules, such as intracellular adhesion molecule- $1 .{ }^{15}$ IMiDs also increase the numbers of T-cells and natural killer cells and augment their function against myeloma cells. ${ }^{16,17}$ Recent research has demonstrated the critical role of the ubiquitously expressed E3 ligase protein cereblon $(\mathrm{CRBN})$ in the mechanism of action of IMiDs. IMiDs bind the endogenous $\mathrm{CRBN}$ and recombinant CRBN-DNA damage binding protein-1 (DDB1) complexes. CRBN depletion is initially cytotoxic to human myeloma cells, but surviving cells with stable CRBN depletion become highly resistant to both drugs, though not to the unrelated drugs bortezomib, dexamethasone, and melphalan. ${ }^{18}$ One of the targets of CRBN is interferon regulatory factor 4 (IRF4), which is critical for myeloma cell survival and is downregulated by IMiD treatment. CRBN is also implicated in many biological pathways affected by IMiDs, such as the downregulation of TNF- $\alpha$ and the T-cell immunomodulatory

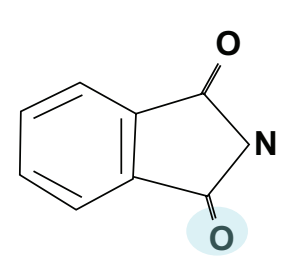

Thalidomide

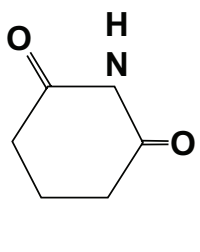

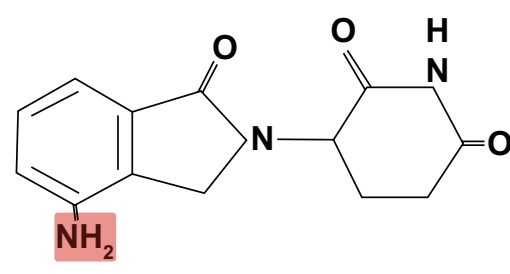

Lenalidomide

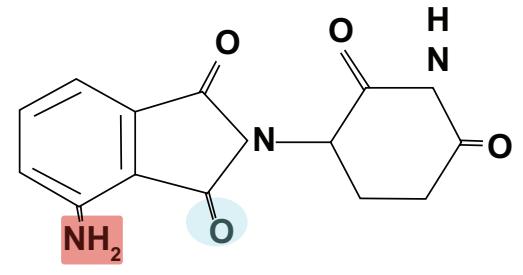

Pomalidomide

Figure I Chemical structure of the immunomodulatory drugs used in the management of myeloma patients. 
activity. ${ }^{19}$ Table 1 summarizes some of the main molecular effects of the IMiDs.

The exact mechanism of action of pomalidomide has not yet been fully characterized. Similar to other IMiDs, pomalidomide has pleotropic activity, as it possesses immunomodulatory, antiangiogenic and anti-myeloma effects. Pomalidomide exerts its anti-myeloma action through direct downregulation of key functions of the tumor cell, as well as by blocking interactions of myeloma cells with their microenvironment via modulation of cell adhesion and decreased production of the key pro-survival cytokines TNF- $\alpha$, IL-6, IL-8, and VEGF. ${ }^{13}$

Immunosurveillance and immune response are defective in MM patients. ${ }^{20}$ The evolution of MM following monoclonal gammopathy of undetermined significance (MGUS) to MM has been attributed to the escape of transformed plasma cells from CD8 (+) T-cell recognition because of impaired antigen processing-presenting machinery. Cytotoxicity assays have demonstrated that MGUS CD8 (+) T-cells lysed autologous transformed plasma cells more than MM CD8 (+) T-cells did. ${ }^{21}$ The CD8+ T-cells show poor recruitment in the bone marrow of symptomatic MM patients. ${ }^{22}$ Pomalidomide can directly stimulate T-cells and increase Th1-type cytokines (interferon- $\gamma$ and IL-2) in vitro, and therefore processes protective, longlasting, tumor-specific, Th1-type responses. ${ }^{23}$

Pomalidomide plays an important role in angiogenesis. Pomalidomide has shown better results regarding the inhibitory action on endothelial sprout formation in a human umbilical artery explant assay in comparison with lenalidomide. In hypoxic conditions, pomalidomide blocked the expression of hypoxia induced factor (HIF) 1a but not HIF $2 \mathrm{a}$ in endothelial cell cultures. ${ }^{24}$

Pomalidomide also has direct anti-myeloma activity. Pomalidomide causes cell cycle arrest in MM cell lines by increasing the level of p21 (WAF-1) expression through a
LSD1-mediated epigenetic mechanism. ${ }^{25}$ WAF1 is a mediator of p53 tumor suppression. ${ }^{26}$

CRBN mediates antiproliferative activities of pomalidomide in myeloma cells, as well as pomalidomide-induced cytokine production in T-cells. ${ }^{27}$ Low CRBN expression is correlated with resistance to IMiDs in MM cell lines and primary MM cells, since acquired deletion of CRBN was found to be the primary genetic event differentiating isogenic MM1.S cell lines either sensitive or resistant to lenalidomide and pomalidomide.

\section{Phase I studies with pomalidomide in multiple myeloma}

The more important clinical studies with pomalidomide in myeloma patients are depicted in Table 2. In order to determine the safety, efficacy, and maximum tolerated dose of pomalidomide, a Phase I study was conducted by Schey et al. ${ }^{28}$ Twenty-four patients with relapsed/refractory MM were recruited. The median number of prior lines of therapy was three (1-6) and seven patients had received previous treatment with thalidomide. Patients were entered into cohorts of three subjects at doses of $1,2,5$, and $10 \mathrm{mg} /$ day. Each cohort was entered after the safety and tolerability of the prior lower-dose cohort had been established after a minimum of 4 weeks of treatment. Nineteen of 24 patients continued on treatment beyond 4 weeks to disease progression or development of a serious adverse event. The maximum tolerated dose of pomalidomide was $2 \mathrm{mg}$. Three patients developed deep vein thrombosis, while grade 4 neutropenia was observed in six patients. Gastrointestinal toxicity grade 1 and 2, skin toxicity grade 1 , and neuropathy grade 1 were reported in four (18\%), four (18\%), five (21\%) and three (16\%) patients, respectively. Grade 1 orthostatic hypotension was reported in two patients receiving 5 and $10 \mathrm{mg}$ of pomalidomide, respectively. In terms of response, 13 patients (54\%) experienced a

Table I Main biological effects of IMiDs

\begin{tabular}{|c|c|}
\hline Molecular effect & Mechanism of action \\
\hline I. Inhibition of angiogenesis ${ }^{9-12}$ & $\begin{array}{l}\text { Inhibition of secretion of VEGF and bFGF inhibition of cytokine-stimulated } \\
\text { endothelial cell migration and cell adhesion. }\end{array}$ \\
\hline 2. Direct induction of apoptosis ${ }^{13}$ & $\begin{array}{l}\text { Induction of apoptosis or GI growth arrest in MM cell lines and in patient } \\
\text { MM cells that are resistant to melphalan, doxorubicin, and dexamethasone. } \\
\text { Enhancement of the anti-MM activity of dexamethasone. }\end{array}$ \\
\hline 3. Indirect induction of apoptosis ${ }^{14-17}$ & $\begin{array}{l}\text { Expansion of T-cells and natural killer cells and augmentation of their } \\
\text { function. Enhancement of activity of caspase-8, increased sensitivity to Fas } \\
\text { induction, inhibition of the expression of the cellular inhibitor of apoptosis } \\
\text { protein-2, and potentiation of other apoptosis inducers, such as TNF-related } \\
\text { apoptosis-inducing ligand. }\end{array}$ \\
\hline 4. CRBN depletion ${ }^{18,19}$ & Downregulation of TNF- $\alpha$ and T-cell immunomodulatory activity. \\
\hline
\end{tabular}

Abbreviations: bFGF, basic fibroblast growth factor; CRBN, cereblon; IMiDs, immunomodulatory drugs; MM, multiple myeloma; TNF, tumor necrosis factor; VEGF, vascular endothelial growth factor. 
Table 2 Results of reported clinical trials of pomalidomide alone or in combination with dexamethasone in relapsed/refractory MM

\begin{tabular}{|c|c|c|c|}
\hline Study & Patients & Response & Adverse events \\
\hline $\begin{array}{l}\text { Phase I study, } \\
\text { Schey et } \mathrm{al}^{28}\end{array}$ & $\begin{array}{l}\text { Patients with relapsed/refractory MM } \\
(n=24 ; 1-6 \text { prior lines of treatment })\end{array}$ & $\begin{array}{l}\text { I } 3(54 \%) \text { patients achieved PR and } \\
4(17 \%) \text { achieved CR }\end{array}$ & $\begin{array}{l}\text { DVT ( } 3 \text { patients; } 12.5 \% \text { ), neutropenia } \\
\text { grade } 4 \text { (6 patients; } 25 \%)\end{array}$ \\
\hline $\begin{array}{l}\text { Phase I study, } \\
\text { Streetly et } \text { al }^{29}\end{array}$ & $\begin{array}{l}\text { Patients with relapsed MM } \\
(n=20 ; 1-7 \text { prior lines of treatment) }\end{array}$ & $\begin{array}{l}2(10 \%) \text { patients achieved CR, } \\
6(30 \%) \text { VGPR, } \\
2(10 \%) \text { PR }\end{array}$ & $\begin{array}{l}\text { Grade } 3 \text { : thrombocytopenia in } \\
3 \text { patients }(15 \%)\end{array}$ \\
\hline $\begin{array}{l}\text { Phase I study, } \\
\text { Richardson et al }{ }^{3 !}\end{array}$ & $\begin{array}{l}\text { Patients with relapsed/refractory MM who } \\
\text { had received bortezomib and lenalidomide } \\
\text { ( } n=38 ; 2-17 \text { prior lines of treatment) }\end{array}$ & $3 \%$ achieved CR, $21 \%$ PR or better & $\begin{array}{l}\text { DLT: grade } 3 / 4 \text { neutropenia }(18 \%) \\
\text { and fatigue }(2.6 \%)\end{array}$ \\
\hline $\begin{array}{l}\text { Phase II study, } \\
\text { Lacy et } \mathrm{al}^{37}\end{array}$ & $\begin{array}{l}\text { Patients who had received at least one but } \\
\text { no more than three prior lines of treatment } \\
\text { ( } n=60 \text {; among these were } 20 \text { patients } \\
\text { refractory to lenalidomide and } 10 \text { patients } \\
\text { refractory to bortezomib) }\end{array}$ & $\begin{array}{l}3(5 \%) \text { patients achieved CR, } \\
\text { I7 (28\%) VGPR, } \\
\text { I8 (30\%) PR } \\
\text { Responses were observed in } 40 \% \\
\text { of lenalidomide- and in } 60 \% \text { of } \\
\text { bortezomib-refractory patients }\end{array}$ & $\begin{array}{l}\text { Grade } 3 / 4 \text { : neutropenia ( } 32 \%) \text {, } \\
\text { anemia }(5 \%) \text {, thrombocytopenia (3\%) }\end{array}$ \\
\hline $\begin{array}{l}\text { Phase II study, } \\
\text { Lacy et } \mathrm{al}^{39}\end{array}$ & $\begin{array}{l}\text { Patients with lenalidomide refractory } \\
\text { disease }(n=34)\end{array}$ & $\begin{array}{l}3(9 \%) \text { patients achieved VGPR, } \\
8(23 \%) \text { PR }\end{array}$ & $\begin{array}{l}\text { Grade } 3 / 4 \text { : neutropenia }(26 \%) \text {, } \\
\text { anemia }(12 \%) \text {, } \\
\text { thrombocytopenia }(9 \%)\end{array}$ \\
\hline $\begin{array}{l}\text { MM-002 } \\
\text { Phase II study, } \\
\text { Jagannath et } \mathrm{al}^{40}\end{array}$ & $\begin{array}{l}\text { Patients with relapsed/refractory } \\
M M(n=I 13)\end{array}$ & $43 \% \geq M R$ & $\begin{array}{l}\text { Grade } 3 / 4 \text { : neutropenia }(41 \%) \text {, } \\
\text { anemia }(22 \%) \text {, pneumonia }(22 \%) \text {, } \\
\text { thrombocytopenia (I9\%), } \\
\text { fatigue ( } 14 \%) \text {, dyspnea }(13 \%) \text {, } \\
\text { urinary tract infection }(9 \%)\end{array}$ \\
\hline $\begin{array}{l}\text { Phase II IFM } \\
\text { 2009-02 study, }\end{array}$ & $\begin{array}{l}\text { Patients with myeloma refractory to both } \\
\text { bortezomib and lenalidomide }(n=84)\end{array}$ & $\begin{array}{l}\text { In arm A, I } 2(30 \%) \text { patients had PR } \\
\text { and better, including } 3 \text { VGPR }\end{array}$ & $\begin{array}{l}\text { Grade } 3 / 4 \text { : neutropenia }(62 \%) \text {, } \\
\text { anemia }(36 \%) \text {, }\end{array}$ \\
\hline Leleu et $\mathrm{al}^{42}$ & $\begin{array}{l}\text { Arm A: } 4 \mathrm{mg} \text { of pomalidomide daily on } \\
\text { days I-2I of each } 28 \text {-day cycle } \\
\text { Arm B: } 4 \mathrm{mg} \text { of pomalidomide continuously } \\
\text { on days I-28 of each } 28 \text {-day cycle }\end{array}$ & $\begin{array}{l}\text { In arm B, I } 7 \text { (47\%) patients had PR } \\
\text { and better, including I VGPR }\end{array}$ & $\begin{array}{l}\text { thrombocytopenia }(27 \%) \text {, } \\
\text { infections }(23 \%)\end{array}$ \\
\hline $\begin{array}{l}\text { MM-003 } \\
\text { Phase III study, } \\
\text { Dimopoulos et al }{ }^{44}\end{array}$ & $\begin{array}{l}\text { Patients with MM refractory to both } \\
\text { bortezomib and lenalidomide }(n=455) \\
\text { Arm A: pomalidomide + low dose Dexa } \\
\text { Arm B: high dose Dexa }\end{array}$ & $\begin{array}{l}\text { Responses have not been } \\
\text { reported yet }\end{array}$ & $\begin{array}{l}\text { Grade } 3 / 4 \text { (arm A vs arm B): } \\
\text { neutropenia ( } 42 \% \text { vs I } \% \text { ), } \\
\text { thrombocytopenia ( } 21 \% \text { vs } 24 \%) \text {, } \\
\text { glucose intolerance ( } 3 \% \text { vs } 7 \%)\end{array}$ \\
\hline
\end{tabular}

Abbreviations: CR, complete response; Dexa, dexamethasone; DLT, dose-limiting toxicity; DVT, deep venous thrombosis; IFM, Intergroupe Francophone du Myélome; MM, multiple myeloma; MR, minimal response; PR, partial response; VGPR, very good partial response.

greater than $50 \%$ reduction in paraprotein and 4 of the total number of patients managed to achieve complete remission (negative immunofixation in serum and urine). The median progression-free survival (PFS) was 28 weeks and the median overall survival (OS) was 90 weeks.

Based on the fact that daily-dose pomalidomide exhibited excellent anti-myeloma activity but was associated with myelosuppression and deep vein thrombosis, another Phase I study was designed by the same team in order to establish the maximum tolerated dose of pomalidomide given on alternate days. ${ }^{29}$ Pomalidomide was given at doses of 1 , 2, 5, and $10 \mathrm{mg}$ on alternate days. Twenty patients with relapsed myeloma were treated. Patients had received at least one prior line of therapy (range 1-7, median 4) and 17 patients had been previously treated with thalidomide. Grade 4 neutropenia occurred in all patients receiving $10 \mathrm{mg}$, in three of ten patients at the $5 \mathrm{mg}$ dose level, in two of four patients at the $2 \mathrm{mg}$ level, and in one of three patients at the $1 \mathrm{mg}$ level. Neutropenia resolved in all patients after the temporary stop of pomalidomide, without the use of growth factors. No thrombotic events were observed despite the fact that no thromboprophylaxis was given. The maximum tolerated dose was defined as $5 \mathrm{mg}$ every other day. Grade 3 thrombocytopenia was observed in two patients. The only nonhematological toxicity reported was tremor in two patients during the first 4 weeks of therapy. Two of $20(10 \%)$ patients attained an immunofixation negative CR, six of $20(30 \%)$ achieved very good partial response (VGPR), two of 20 (10\%) had partial response (PR), one of $20(5 \%)$ had minimal response (MR), and six of $20(30 \%)$ had stable disease (SD) according to European Group for Blood and Marrow Transplant (EBMT) response criteria. ${ }^{30}$ Two patients had progressive disease (PD). The median PFS and OS were 10.5 and 33 months, respectively. When dexamethasone was added to pomalidomide in nine (41\%) patients (in two because of prolonged nonresponsive disease 
and in seven because of disease progression after a median of 23 weeks [range 15-90 weeks] of monotherapy), responses were improved. In conclusion, alternate-day pomalidomide retained anti-myeloma effect with reduced adverse events.

In the two Phase I trials discussed previously, treatment with pomalidomide was associated with significantly increased serum IL-2 receptor and IL-12 levels, which is consistent with activation of T-cells and monocytes and macrophages, as well as with significant rise in the number of NK cells and the proportion of CD8 (+) cells. ${ }^{28,29}$ These observations confirm in vivo the immunomodulatory properties of pomalidomide.

Another open-label, Phase I, dose-escalation study was conducted to evaluate the maximum tolerated dose of pomalidomide when given for 21 days of each 28-day cycle in patients with relapsed/refractory MM who had previously received multiple lines of treatment, including bortezomib and lenalidomide. ${ }^{31}$ A total of 38 patients were enrolled into four pomalidomide dose-level cohorts: $2 \mathrm{mg}$ $(\mathrm{n}=6) ; 3 \mathrm{mg}(\mathrm{n}=8) ; 4 \mathrm{mg}(\mathrm{n}=14)$; and $5 \mathrm{mg}(\mathrm{n}=10)$. Patients had received a median of six prior anti-myeloma treatments (range, 2-17). Sixty-three percent of the patients were refractory to lenalidomide/bortezomib combination treatment. All patients received aspirin, 81-100 mg/day, or another form of thromboprophylaxis. After four cycles, patients who progressed or had not achieved MR could receive dexamethasone, $40 \mathrm{mg} /$ week. The most common grade 3 or 4 adverse events included neutropenia, anemia, thrombocytopenia, and fatigue. Since there were four doselimiting toxicities (grade 4 neutropenia) at $5 \mathrm{mg} /$ day, the maximum tolerated dose was determined as $4 \mathrm{mg} /$ day. Venous thromboembolism rates were very low $(\leq 5 \%)$. Forty-two percent of the patients achieved MR or better, $21 \% \mathrm{PR}$ or better, and 3\% CR. Median duration of response, PFS, and OS were 4.6, 4.6, and 18.3 months, respectively. The study concluded that pomalidomide $4 \mathrm{mg}$ /day on days 1 to 21 of each 28-day cycle, with or without dexamethasone (40 mg/week), has encouraging activity with manageable toxicity in relapsed/refractory MM.

Since the combination of an IMiD (lenalidomide), the proteasome inhibitor bortezomib, and dexamethasone has shown promising efficacy both as frontline and salvage treatment in myeloma patients, ${ }^{32,33}$ a Phase I study was designed in patients with relapsed/refractory MM to identify the maximum tolerated dose of pomalidomide in combination with bortezomib and low-dose dexamethasone. ${ }^{34}$ Patients were treated with escalating doses of oral pomalidomide on days 1-14, intravenous bortezomib on days 1, 4, 8, and 11 , and oral dexamethasone $(20 \mathrm{mg}$ or $10 \mathrm{mg}$ for patients $\leq 75$ or $>75$ years of age, respectively) on days 1 , $2,4,5,8,9,11$, and 12 in 21-day cycles. All patients received thromboprophylaxis and were lenalidomide-refractory. The study is still ongoing, but it appears that pomalidomide from $1 \mathrm{mg}$ up to $3 \mathrm{mg}$ dose levels in combination with $1 \mathrm{mg} / \mathrm{m}^{2}$ of intravenous bortezomib and oral dexamethasone is well tolerated with rapid onset of response and promising clinical activity in lenalidomide-refractory patients. Two more ongoing Phase I studies combine pomalidomide/ dexamethasone with cyclophosphamide or pegylated liposomal doxorubicin show effectiveness and manageable toxicity in patients with relapsed/refractory $\mathrm{MM}^{35,36}$

\section{Phase II studies in myeloma patients}

In the first reported Phase II trial, 60 patients with relapsed/ refractory $\mathrm{MM}$, who had received at least one but no more than three prior lines of treatment, were enrolled. ${ }^{37}$ Pomalidomide was administered orally at a dose of $2 \mathrm{mg}$ daily on days 1 through 28 of a 28-day cycle. Dexamethasone $40 \mathrm{mg}$ daily was administered orally on days $1,8,15$, and 22 of each cycle. Twenty-one patients had received prior lenalidomide-based regimens, 28 prior thalidomide, and 20 prior bortezomibbased therapy. Among them, 20 patients were considered refractory to lenalidomide, 16 to thalidomide and ten to bortezomib. Nineteen patients (32\%) were classified as high risk according to their cytogenetic profile. Thirty-eight patients $(63 \%)$ achieved confirmed response, including CR in three patients $(5 \%)$, VGPR in 17 patients $(28 \%)$, and PR in 18 patients (30\%) according to the International Myeloma Working Group (IMWG) response criteria. ${ }^{38}$ Responses were observed in $40 \%$ of lenalidomide-refractory patients, $37 \%$ of thalidomide-refractory patients, $60 \%$ of bortezomib-refractory patients, and $74 \%$ of patients with high-risk cytogenetic or molecular markers. The most common adverse events were neutropenia (35\%), fatigue (17\%), and pneumonia ( $8 \%$ ). Four of the 14 patients that reported neuropathy at baseline experienced worsening during treatment. Only one patient had a thromboembolic event. The median PFS was 11.6 months.

The previous trial ${ }^{37}$ suggested significant activity of pomalidomide in lenalidomide-refractory disease, indicating that there is no cross-resistance between the two compounds. To further define the efficacy of the pomalidomide/ dexamethasone combination in this setting, a cohort of 34 patients with lenalidomide-refractory disease was studied by Lacy et al. ${ }^{39}$ Pomalidomide was administered orally at a dose of $2 \mathrm{mg}$ continuously in 28-day cycles along with $40 \mathrm{mg}$ dexamethasone given weekly. The overall response 
rate was 47\%: VGPR in three (9\%) patients, PR in eight $(23 \%), \mathrm{SD}$ in $12(35 \%)$ and $\mathrm{PD}$ in six (18\%), according to IMWG response criteria. The median time to response, PFS, and OS were 2, 9.1, and 13.9 months respectively. Hematologic grade 3 or 4 toxicity was seen in 18 patients (53\%), consisting of anemia (12\%), thrombocytopenia (9\%), and neutropenia (26\%).

The MM-002 Phase II study ${ }^{40}$ evaluated the safety and efficacy of oral pomalidomide in combination with low-dose dexamethasone in patients with relapsed/refractory MM, using a "lenalidomide-like" dosing schedule: pomalidomide at a dose of $4 \mathrm{mg}$ /day for days 1-21 of a 28-day cycle and $40 \mathrm{mg}$ dexamethasone given weekly. All patients received mandatory thromboprophylaxis. The analysis included 113 patients who had received at least two prior therapies (including lenalidomide and bortezomib) and had had disease progression within 60 days of their last treatment. The overall response ( $\geq$ MR according to EBMT criteria ${ }^{30}$ ) was $43 \%$. The most common grade 3 or 4 adverse events were neutropenia (41\%), anemia (22\%), pneumonia (22\%), thrombocytopenia (19\%), fatigue (14\%), dyspnea (13\%), leukopenia $(10 \%)$, back pain (10\%), and urinary tract infection (9\%), leading to at least one dose reduction in $26 \%$ of patients. ${ }^{40}$

Two Phase II studies ${ }^{41,42}$ have evaluated the efficacy of pomalidomide plus low-dose dexamethasone in myeloma refractory to both bortezomib and lenalidomide. In the first trial, ${ }^{41}$ pomalidomide, 2 or $4 \mathrm{mg}$ daily, was given orally with dexamethasone $40 \mathrm{mg}$ weekly, with 35 patients enrolled in each cohort. ${ }^{41}$ The overall response in the $2 \mathrm{mg}$ cohort was $49 \%$ : VGPR in five (14\%), PR in four (11\%), and MR in eight $(23 \%)$ patients. In the 4-mg cohort, confirmed responses consisted of CR in one (3\%), VGPR in three (9\%), PR in six $(17 \%)$, and MR in five (14\%) patients, for an overall response rate of $43 \%$. Overall survival at 6 months was $78 \%$ and $67 \%$ in the 2 and $4 \mathrm{mg}$ cohort, respectively. These nonrandomized data suggest no advantage for $4 \mathrm{mg}$ over $2 \mathrm{mg}$ daily. The Intergroupe Francophone du Myélome (IFM) 2009-02 study ${ }^{42}$ included 84 patients who were randomized to either $4 \mathrm{mg}$ of pomalidomide daily on days 1-21 of each 28 days (arm $A, n=43$ ) or continuously on days 1-28 of each 28 days (arm $B, n=41$ ). Dexamethasone was given orally at $40 \mathrm{mg}$ daily on days $1,8,15$, and 22 of each cycle to all patients. All patients received thromboprophylaxis. Overall response rate was 35\% (arm A 21/28) and 34\% (arm B 28/28), independent of the number of prior lines and level of refractoriness. Median duration of response, time to disease progression, and PFS were 7.3, 5.4, and 4.6 months, respectively, which was similar across cohorts. At 23 months' follow-up, median OS was 14.9 months, with $44 \%$ of the patients alive at 18 months. Toxicity consisted primarily of myelosuppression, which was manageable. ${ }^{42}$

Pomalidomide also proved efficient in extramedullary disease in patients with relapsed refractory MM enrolled in a Phase II clinical trial of pomalidomide plus low-dose dexamethasone at Mayo Clinic. ${ }^{43}$ Extramedullary disease was present at the time of trial entry in $7.5 \%(13 / 174)$ of patients. The response of extramedullary disease to pomalidomide plus low-dose dexamethasone included two complete and two partial responses among the 13 patients (response rate, $31 \%$ ) (Table 2 ).

\section{Phase III trials in patients with relapsed/refractory myeloma}

The first results of MM-003, an open-label, multicenter, Phase III trial designed to compare the efficacy and safety of pomalidomide plus low-dose dexamethasone versus highdose dexamethasone in a population of patients refractory to both lenalidomide and bortezomib, were recently reported at the American Society of Hematology 2012 meeting. ${ }^{44}$ Four hundred and fifty-five patients were randomized 2:1 to receive either pomalidomide plus low-dose dexamethasone ( $\operatorname{arm~A}$, $\mathrm{n}=302$ ) or high-dose dexamethasone alone ( $\operatorname{arm} \mathrm{B}, \mathrm{n}=153$ ). Patients in arm A received pomalidomide $4 \mathrm{mg}$ on days $1-21$ and dexamethasone $40 \mathrm{mg}$ (20 $\mathrm{mg}$ for patients $>75$ years of age) on days $1,8,15$, and 22 in a 28 -day cycle. Patients in arm B received dexamethasone $40 \mathrm{mg}(20 \mathrm{mg}$ for patients $>75$ years of age) on days 1-4, 9-12, and 17-20 in a 28-day cycle. Patients progressing on arm B had the opportunity to receive pomalidomide in the companion trial, MM-003C. Treatment was continued until progressive disease or unacceptable toxicity. At the time of analysis, $45 \%$ of patients in arm A and $25 \%$ of patients in arm B remained on-study. The median number of prior therapies was five (range, 1-17). Seventy-two percent of patients were refractory to both lenalidomide and bortezomib. At the PFS final analysis, with a median follow-up of 18 weeks, PFS was significantly longer with pomalidomide plus low-dose dexamethasone versus dexamethasone alone (median 15.7 vs 8.0 weeks; 267 total events; hazard ratio $0.45 ; P<0.001$ ). OS (interim analysis) was also significantly longer with pomalidomide plus low-dose dexamethasone versus dexamethasone alone (median not reached vs 34 weeks; 134 events; hazard ratio $0.53 ; P<0.001)$. This included 45 patients who received pomalidomide after progressing on high-dose dexamethasone. Median duration of treatment was 12.4 weeks in arm A and 8 weeks in arm B. Following Data 
and Safety Monitoring Board (DSMB) review of the data, immediate crossover of arm B patients to arm A was recommended. Overall, 25\% of patients in arm A and 38\% in arm B died, with progressive disease and infections as the primary reasons. Frequent grade 3/4 hematologic toxicities included neutropenia (42\% in arm A vs $15 \%$ in arm B), thrombocytopenia (21\% vs $24 \%$ ), and febrile neutropenia (7\% vs $0 \%$ ). Other toxicities (grade $3 / 4$ ) included infections ( $24 \%$ vs $23 \%$ ), hemorrhage ( $3 \%$ vs $5 \%$ ), glucose intolerance ( $3 \%$ vs $7 \%$ ), neuropathy ( $1 \%$ vs $1 \%$ ), and venous thromboembolism ( $1 \%$ vs $0 \%)$. The primary reason for discontinuation was progressive disease: $35 \%$ in arm $\mathrm{A}$ and $49 \%$ in arm B (Table 2).

\section{Conclusion}

Pomalidomide represents a novel drug for the treatment of refractory/relapsed MM and provides a good example of how our understanding of the clinical, molecular, and genetic features of hematologic malignancies can be used to improve patient outcomes. The direct effect of pomalidomide on myeloma cells, as well as the modulation of bone marrow microenvironment, is translated into clinical efficacy even in heavily pretreated patients. The encouraging results of Phase III trials provide the rationale for its use in combination with dexamethasone in patients who fail multiple lines of treatment, including bortezomib- and lenalidomide-based regimens. The toxicity is manageable and there is the advantage of oral administration. The combinations with alkylating agents, proteasome inhibitors, or other novel compounds will probably further improve response rates, and the results of more randomized clinical trials are eagerly awaited.

\section{Disclosure}

MAD has received honoraria from Celgene Corporation, Summit, NJ, USA. The authors report no other conflicts of interest in this work.

\section{References}

1. Jemal A, Siegel R, Xu J, Ward E. Cancer statistics. CA Cancer J Clin. 2010;60(5):277-300.

2. Kyle RA, Rajkumar SV. Multiple myeloma. N Engl J Med. 2004; 351(18):1860-1873.

3. Laubach JP, Schlossman RL, Mitsiades CS, Anderson KC, Richardson PG. Thalidomide, lenalidomide and bortezomib in the management of newly diagnosed multiple myeloma. Expert Rev Hematol. 2011;4(1):51-60.

4. van de Donk NW, Lokhorst HM, Dimopoulos M, et al. Treatment of relapsed and refractory multiple myeloma in the era of novel agents. Cancer Treat Rev. 2011;37(4):266-283.

5. Singhal S, Mehta J, Desikan R, et al. Antitumor activity of thalidomide in refractory multiple myeloma. $N$ Engl J Med. 1999; 341(21):1565-1571.

6. Anderson KC. Lenalidomide and thalidomide: mechanisms of actionsimilarities and differences. Semin Hematol. 2005;42(4 Suppl 4):S3-S8.
7. Hoffmann M, Kasserra C, Reyes J, et al. Absorption, metabolism and excretion of $[14 \mathrm{C}]$ pomalidomide in humans following oral administration. Cancer Chemother Pharmacol. 2013;71(2):489-501.

8. Rajkumar SV, Kyle RA. Angiogenesis in multiple myeloma. Semin Oncol. 2001;28(6):560-564.

9. Reddy N, Hernandez-Ilizaliturri FJ, Deeb G, et al. Immunomodulatory drugs stimulate natural killer-cell function, alter cytokine production by dendritic cells, and inhibit angiogenesis enhancing the anti-tumour activity of rituximab in vivo. Br J Haematol. 2008;140(1):36-45.

10. Dredge K, Marriott JB, Macdonald CD, et al. Novel thalidomide analogues display anti-angiogenic activity independently of immunomodulatory effects. Br J Cancer. 2002;87(10):1166-1172.

11. Vacca A, Scavelli C, Montefusco V, et al. Thalidomide downregulates angiogenic genes in bone marrow endothelial cells of patients with active multiple myeloma. J Clin Oncol. 2005;23(23):5334-5346.

12. Dredge K, Horsfall R, Robinson SP, et al. Orally administered lenalidomide (CC-5013) is anti-angiogenic in vivo and inhibits endothelial cell migration and Akt phosphorylation in vitro. Microvasc Res. 2005;69(1-2):56-63.

13. Hideshima T, Chauhan D, Shima Y, et al. Thalidomide and its analogs overcome drug resistance of human multiple myeloma cells to conventional therapy. Blood. 2000;96(9):2943-2950.

14. Mitsiades N, Mitsiades CS, Poulaki V, et al. Apoptotic signaling induced by immunomodulatory thalidomide analogs in human multiple myeloma cells: therapeutic implications. Blood. 2002;99(12):4525-4530.

15. Nogueira AC, Neubert R, Helge H, Neubert D. Thalidomide and the immune system. 3. Simultaneous up- and down-regulation of different integrin receptors on human white blood cells. Life Sci. 1994; 55(2):77-92.

16. Davies FE, Raje N, Hideshima T, et al. Thalidomide and immunomodulatory derivatives augment natural killer cell cytotoxicity in multiple myeloma. Blood. 2001;98(1):210-216.

17. Zhu D, Corral LG, Fleming YW, Stein B. Immunomodulatory drugs Revlimid (lenalidomide) and CC-4047 induce apoptosis of both hematological and solid tumor cells through NK cell activation. Cancer Immunol Immunother. 2008;57(12):1849-1859.

18. Zhu YX, Braggio E, Shi CX, et al. Cereblon expression is required for the antimyeloma activity of lenalidomide and pomalidomide. Blood. 2011;118(18):4771-4779.

19. Zhu YX, Kortuem KM, Stewart AK. Molecular mechanism of action of immune-modulatory drugs thalidomide, lenalidomide and pomalidomide in multiple myeloma. Leuk Lymphoma. 2013;54(4):683-687.

20. Pratt G, Goodyear O, Moss P. Immunodeficiency and immunotherapy in multiple myeloma. Br J Haematol. 2007;138(5):563-579.

21. Racanelli V, Leone P, Frassanito MA, et al. Alterations in the antigen processing-presenting machinery of transformed plasma cells are associated with reduced recognition by $\mathrm{CD} 8+\mathrm{T}$ cells and characterize the progression of MGUS to multiple myeloma. Blood. 2010; 115(6):1185-1193.

22. Goodyear OC, Pratt G, McLarnon A, et al. Differential pattern of $\mathrm{CD} 4+$ andCD8+ T-cell immunity to MAGE-A1/A2/A3 in patients with monoclonal gammopathy of undetermined significance (MGUS) and multiple myeloma. Blood. 2008;112(8):3362-3372.

23. Dredge K, Marriott JB, Todryk SM, et al. Protective antitumor immunity induced by a costimulatory thalidomide analog in conjunction with whole tumor cell vaccination is mediated by increased Th1-type immunity. J Immunol. 2002;168(10):4914-4919.

24. Lu L, Payvandi F, Wu L, et al. The anti-cancer drug lenalidomide inhibits angiogenesis and metastasis via multiple inhibitory effects on endothelial cell function in normoxic and hypoxic conditions. Microvasc Res. 2009;77(2):78-86.

25. Escoubet-Lozach L, Lin IL, Jensen-Pergakes K, et al. Pomalidomide and lenalidomide induce p 21 WAF-1 expression in both lymphoma and multiple myeloma through a LSD1-mediated epigenetic mechanism. Cancer Res. 2009;69(18):7347-7356.

26. El-Deiry WS, Tokino T, Velculescu VE, et al. WAF1, a potential mediator of p53 tumor suppression. Cell. 1993;75(4):817-825. 
27. Lopez-Girona A, Mendy D, Ito T, et al. Cereblon is a direct protein target for immunomodulatory and antiproliferative activities of lenalidomide and pomalidomide. Leukemia. 2012;26(11):2326-2335.

28. Schey SA, Fields P, Bartlett JB, et al. Phase I study of an immunomodulatory thalidomide analog, CC-4047, in relapsed or refractory multiple myeloma. J Clin Oncol. 2004;22(16):3269-3276.

29. Streetly MJ, Gyertson K, Daniel Y, Zeldis JB, Kazmi M, Schey SA. Alternate day pomalidomide retains anti-myeloma effect with reduced adverse events and evidence of in vivo immunomodulation. $\mathrm{Br} J$ Haematol. 2008;141(1):41-51.

30. Bladé J, Samson D, Reece D, et al. Criteria for evaluating disease response and progression in patients with multiple myeloma treated by high-dose therapy and haemopoietic stem cell transplantation. Myeloma Subcommittee of the EBMT. European Group for Blood and Marrow Transplant. Br J Haematol. 1998;102(5):1115-1123.

31. Richardson PG, Siegel D, Baz R, et al. Phase I study of pomalidomide MTD, safety and efficacy in patients with refractory multiple myeloma who have received lenalidomide and bortezomib. Blood. 2013; 121(11):1961-1967.

32. Richardson PG, Weller E, Lonial S, et al. Lenalidomide, bortezomib, and dexamethasone combination therapy in patients with newly diagnosed multiple myeloma. Blood. 2010;116(5):679-686.

33. Dimopoulos MA, Kastritis E, Christoulas D, et al. Treatment of patients with relapsed/refractory multiple myeloma with lenalidomide and dexamethasone with or without bortezomib: prospective evaluation of the impact of cytogenetic abnormalities and of previous therapies. Leukemia. 2010;24(10):1769-1778.

34. Richardson PG, Hofmeister CC, Siegel D, et al. MM-005: a phase 1, multicenter, open-label, dose-escalation study to determine the maximum tolerated dose for the combination of pomalidomide, bortezomib, and low-dose dexamethasone in subjects with relapsed or refractory multiple myeloma. Paper presented at: 54th Annual Meeting of the American Society of Hematology; December 8-11, 2012; Atlanta, GA, USA.

35. Baz R, Shain KH, Alsina M, et al. Oral weekly cyclophosphamide in combination with pomalidomide and dexamethasone for relapsed and refractory myeloma: report of the dose escalation cohort. Paper presented at: 54th Annual Meeting of the American Society of Hematology; December 8-11, 2012; Atlanta, GA, USA.

36. Berenson JR, Hilger JD, Klein LM, et al. A Phase $1 / 2$ Study of pomalidomide, dexamethasone and pegylated liposomal doxorubicin for patients with relapsed/refractory multiple myeloma. Paper presented at: 54th Annual Meeting of the American Society of Hematology; December 8-11, 2012; Atlanta, GA, USA.
37. Lacy MQ, Hayman SR, Gertz MA, et al. Pomalidomide (CC4047) plus low-dose dexamethasone as therapy for relapsed multiple myeloma. J Clin Oncol. 2009;27(30):5008-5014.

38. Durie BG, Harousseau JL, Miguel JS, et al. International uniform response criteria for multiple myeloma. Leukemia. 2006;20(9):1467-1473.

39. Lacy MQ, Hayman SR, Gertz MA, et al. Pomalidomide (CC4047) plus low dose dexamethasone (Pom/dex) is active and well tolerated in lenalidomide refractory multiple myeloma (MM). Leukemia. 2010; 24(11):1934-1939.

40. Jagannath S, Hofmeister CC, Siegel DS, et al. Pomalidomide (POM) with Low-Dose Dexamethasone (LoDex) in Patients (Pts) with Relapsed and Refractory Multiple Myeloma Who Have Received Prior Therapy with Lenalidomide (LEN) and Bortezomib (BORT): Updated Phase 2 Results and Age Subgroup Analysis. Paper presented at: 54th Annual Meeting of the American Society of Hematology; December 8-11, 2012; Atlanta, GA, USA.

41. Lacy MQ, Allred JB, Gertz MA, et al. Pomalidomide plus lowdose dexamethasone in myeloma refractory to both bortezomib and lenalidomide: comparison of 2 dosing strategies in dual-refractory disease. Blood. 2011;118(11):2970-2975.

42. Leleu X, Attal M, Arnulf B, et al; Intergroupe Francophone du Myélome. Pomalidomide plus low-dose dexamethasone is active and well tolerated in bortezomib and lenalidomide-refractory multiple myeloma: Intergroupe Francophone du Myelome 2009-02. Blood. 2013;121(11):1968-1975.

43. Short KD, Rajkumar SV, Larson D, et al. Incidence of extramedullary disease in patients with multiple myeloma in the era of novel therapy, and the activity of pomalidomide on extramedullary myeloma. Leukemia. 2011;25(6):906-908.

44. Dimopoulos MA, Lacy MQ, Moreau P, et al. Pomalidomide in combination with low-dose dexamethasone: demonstrates a significant progression free survival and overall survival advantage, in relapsed/ refractory mm: a phase 3 , multicenter, randomized, open-label study. Paper presented at: 54th Annual Meeting of the American Society of Hematology; December 8-11, 2012; Atlanta, GA, USA.
OncoTargets and Therapy

\section{Publish your work in this journal}

OncoTargets and Therapy is an international, peer-reviewed, open access journal focusing on the pathological basis of all cancers, potential targets for therapy and treatment protocols employed to improve the management of cancer patients. The journal also focuses on the impact of management programs and new therapeutic agents and protocols on

\section{Dovepress}

patient perspectives such as quality of life, adherence and satisfaction The manuscript management system is completely online and includes a very quick and fair peer-review system, which is all easy to use. Visit http://www.dovepress.com/testimonials.php to read real quotes from published authors. 